\title{
DOSSIÊ: COMUNICAÇÃO, PÚBLICO E RECEPÇÃO ATENÇÕES E VISÕES NA AMPLITUDE E DIVERSIDADE MUSEOLÓGICA
}

\author{
Marilia Xavier Cury'
}

Não seria demasiado dizer que a instituição museu sempre esteve voltada à comunicação, se dissermos ao mesmo tempo que o ato de coletar esteve associado a expor ao olhar de outros aquilo que se tem por uma determinada formação. Igualmente o público sempre fez parte da ideia de museu, pois a comunicação depende de, ao menos, duas pessoas e, no caso do museu, alguém interno a ele e outro externo: quem coleciona quer ter para quem mostrar - os objetos - e demonstrar a sua capacidade de reunir, possuir e saber. $\bigcirc$ público, desde há muito tempo, é o visitante do museu, para o qual a instituição se abriu mais ou menos, a depender das circunstâncias históricas, sociais e culturais.

Apesar da remissão remota, o que podemos entender hoje como comunicação, agora saindo da generalidade, vem atravessando o século $X X$, entrando no XXI como muitas e diversificadas possibilidades epistemológicas, paradigmáticas, teóricas e metodológicas, como nos informa a área da Comunicação. Igualmente a ideia de público vem se transformando, também e porque associa-se à comunicação nas suas quase que infinitas teorizações, assim como a outros campos como a Antropologia, Sociologia e Educação.

Os marcos que colocam os museus em outros patamares sociais já foram muitas vezes apresentados, mas se buscamos referenciais para as ideias de comunicação e público na aproximação com os museus não podemos deixar de lembrar a criação do Conselho Internacional de Museus (ICOM) que no momento pós II Grande Guerra Mundial recoloca a pergunta sobre a função social dessas instituições. Ainda, o movimento Maio de 1968, o debate museu templo ou fórum, o advento da Nova Museologia e daí por diante, não há retrocesso para os museus na sua perspectiva social e com isto a comunicação e o público ganham destacada atenção. É de Duncan Cameron o clássico artigo "The museum: a temple or the fórum" (1970), María Bolaños nos apresenta artigos organizados no conjunto que denominou Formas de antimuseus (2002) e os Documentos de Santiago do Chile (1972) e do Quebec (1984) nos apresentam as inovações daqueles momentos que chegam até a atualidade, agora como desafios pragmáticos a serem vencidos para que o museu seja, de fato, um agente de comunicação para uma diversidade de públicos.

No entanto, o que ainda pode nos surpreender e nos levar a questionar é: por que o museu tardou tanto para abraçar a comunicação como parte de sua

I Docente do Museu de Arqueologia e Etnologia da Universidade de São Paulo. Museóloga e educadora de museu. 
problemática de trabalho, a comunicação museal, e de estudo, a comunicação museológica? Se o museu sempre foi um lugar de comunicação e se a área de comunicação teve grandes transformações no século $X X$, por que o museu e a Museologia resistiram a essa abordagem como trabalho museal e de produção de conhecimento museológico? Perguntas difíceis de serem respondidas rápida e brevemente, mas podemos indagar. Por exemplo, o mesmo Duncan Cameron, que em 1970 publicou seu renomado artigo sobre como o museu deveria se entender e ser entendido socialmente - "The museum: a temple or the fórum" -, publicou em 1968 "A viewpoint: the museum as a communications system and implications for museum education", o artigo com ideias estruturadas na "Teoria matemática da comunicação", de 1949, no modelo original de Claude E. Shannon e W. Weaver, desenvolvido para explicar a comunicação elétrica, quando na década de 1960 a Comunicação já apresentava inúmeras teorias e modelos comunicacionais voltados aos estudos que já realizava intensamente. Resumidamente, Cameron em seu artigo de 1968 insere a relação transmissor (expositor)/meio (coisas reais)/receptor (visitante), mas nos parâmetros matemáticos, ideia seguida por Knez e Wright (1970), com a adaptação para curador (determina o conteúdo da mensagem)/exposição (codifica a mensagem, o objeto é o meio principal, e as etiquetas e fotografias o meio secundário)/visitante (decodifica a mensagem). Somente em 1989 Roger Miles recoloca essa relação de forma a flexibilizar os papéis, pois o feedback do processo serviu, então, para realimentar inúmeras vezes a visão do emissor, considerando as interpretações do visitante que o emissor gostaria de conhecer. Muitas década se passaram para que as relações em desequilíbrio entre emissor e receptor fossem alteradas, para que possamos hoje ter outros parâmetros para a prática comunicacional nos museus e, mais ainda, para os estudos que envolvam a comunicação museológica como subárea da museologia e possibilidades de pesquisa em face dos compromissos da instituição e do campo atualizados. No entanto, novos equilíbrios são vislumbrados, pois o museu se reconstrói em elaborações e estatutos conceituais, práticas e relações de inserção social. Também a curadoria de coleções museológicas se renova, constrói novas premissas, sentidos e ressignificações, estrutura narrativas e retóricas, enunciações, representações, interpretações atualizadas e formas abertas e criativas de apropriação pelo público das mensagens museológicas. A Comunicação já nos ensinou que a teia de ações curatoriais em um museu não se dissocia das formas de veiculação de mensagens pela instituição (não somente no museu) e da recepção, aqui entendida como um processo que antecede e sucede a experiência museal. Por isso, a escolha temática deste dossiê, embora abrangente, se explica na ideia de que a comunicação, ao unir as condições de produção (a produção de conhecimento e a práxis do museu) à veiculação (ou o meio, a exposição, por exemplo) e à recepção, contribui para que a eficácia seja entendida como um processo complexo e dinâmico dentro de um sistema a ser enfrentado.

A questão é: comunicação é uma forma de entender e estudar o museu, de problematizá-lo enfim, em se tratando da curadoria das coleções, mas também da participação do público na instituição, nos processos comunicacionais e igualmente como problemática a ser tratada para a produção de conhecimento da práxis, a museografia, ou da área, a Museologia.

A recepção é, nesse sentido, ora parte da comunicação, ora parte do público como tema da instituição e da pesquisa museológica. No entanto, é também 
ponto de vista desde onde se vê e se estuda o museu e o processo de comunicação, posto que sempre há um ponto de vista, um lugar desde onde se dá a observação e a análise. Mas, recepção refere-se principal aos estudos ou pesquisa de recepção que, em síntese, são as abordagens culturais sobre as formas de uso e apropriação do museu pelos distintos públicos (CURY, 2005; CURY, 2009), estudos que se dão a partir de correntes e/ou tendências diversas, uma vez que estas pesquisas partiram dos Estudos Culturais (Cultural Studies) ou de alguma forma fazem parte destes, mas com outras modelagens (LOPES, 1993).

A questão que se coloca é que a comunicação, o público e a recepção são temas relativamente novos para os museus e a Museologia e ainda abertos, porque estão em consolidação e porque as perspectivas, abordagens e possibilidades são as mais diversas possíveis, o que considero pontos bastante estimulantes e criativos, mas desafiadores. Então, temos que lidar, além daqueles próprios aos museus e Museologia, com a interdisciplinaridade ou mesmo a transversalidade para tratar da comunicação, do público e para desenvolver estudos de recepção, pois são diálogos e confrontos que precisam ser travados também com a ajuda da Antropologia, Sociologia, História, Educação, Psicologia dentre outras e para citar algumas que não podem ser omitidas.

O dossiê que ora apresentamos é o reflexo do dinamismo do recorte Comunicação, Público e Recepção, de seus inúmeros ângulos de visão, historiografias, perspectivas e premissas. Sabemos que é amplo, mas não foi o nosso intuito revisá-lo e muito menos esgotá-lo, mas tivemos como objetivo reunir um conjunto de autores que dessem conta da diversidade, para ilustrar como cada tema e os três como um eixo podem ser abordados e aprofundados. Ora, então, apresentamos os autores que atenderam ao convite para elaborarem seus artigos para este dossiê.

O primeiro artigo é de autoria de Maria Marta Reca, antropóloga do Museu de La Plata, uma instituição universitária argentina que carrega os desafios de seus mais de 100 anos de existência. Reca afirma que estratégias de comunicação podem fortalecer “... um perfil atualizado da instituição museu”. A pesquisadora faz a etnografia da instituição onde trabalha por meio da exposição de longa duração "Espejos culturales”, destacando a intencionalidade comunicacional da exposição, com o auxílio de um estudo de público realizado sob o aporte da semiótica, recorrendo ao método qualitativo e à análise do discurso.

A Museologia crítica é para Maria Marta Reca o campo de análise formado por diversas disciplinas para uma reflexão profunda da museografia - o fazer museal - e da experiência de visita. Igualmente é para educadora Silvia Alderoqui que ainda “... concibe a los museos como espacios de diálogo, conflicto, tradición, contradicción, resistencia, colisiones, fusiones y transformación social", o que para a educadora significa uma grande mudança no pensamento e rotina institucional. Para Alderoqui as questões comunicacionais passam pelo fato de que "La igualdad del derecho a los bienes culturales comunes no se corresponde con las igualdades de hecho" e que essa questão é remota, lembra a importância dos Documentos do ICOM como a Declaração de Quebec (1984), mas demonstra o seu estranhamento com a literatura ao esquecimento do Seminário no Museu da Cidade de Nova York, 9 e 10 de outubro de 1967, quando Marshall McLuhan e Harley Parker apontam diversos problemas de comunicação dos museus e exposições desse período, sempre, obviamente como comunicólogos, ressaltando dificuldades institucionais na relação com o público. 
A autora aborda a "Curadoria do visitante" como forma de participação do público nos processos museais, revelando que a curadoria de exposição pode ser vista ampliadamente. De outro ponto de vista, mas tendo a curadoria participativa como referência importante, Louise Alfonso Prado e Marcia Lika Hattori nos apresentam relato importante sobre um processo expográfico para a inauguração do Museu Histórico e Arqueológico de Lins, SP, com a participação de indígenas Kaingang e Terena residentes na Terra Indígena Icatu, Braúna, São Paulo. O título "Tensões sobre a construção narrativa das histórias indígenas no museu" já nos induz ao entendimento de que as agentes, Louise, antropóloga, e Marcia, educadora de museu e arqueóloga, viram o resultado do processo positivamente, quanto ao protagonismo dos grupos indígenas, e criticamente, quanto à descontinuidade de processo de participação e comunicação institucional devido à troca de gestão municipal, o que nos leva a crer que a questão da comunicação abarca mais pessoas, níveis decisórios e estruturas de pensamento, objetivos e políticas públicas solidamente construídas.

A contribuição que François Mairesse refere-se à mediação, comumente associada à comunicação. Com fundamentação histórica e conceitual, Mairesse aproxima dois pontos de vista aparentemente distintos: a comunicação e o marketing museal. Nesse sentido, o autor nos demonstra como o museu, para atingir seus objetivos de sustentabilidade, apropria-se do sistema comunicacional e, em consequência, da ideia de mediação, para atingir seus objetivos de visibilidade, atração de público e de recursos. $O$ autor nos coloca para discussão conflitos gerados entre visões sobre o visitante e, no limite, como o marketing pode alterar a relação do museu com o visitante "de não mais ser visto como parte constitutiva do público, instância de decisão e de reflexão dentro do processo democrático, para se tornar apenas um consumidor isolado entre outros, identificado apenas em função do seu poder aquisitivo".

Com atenção aos museus de História e à historiografia dos museus, Cecília Helena de Salles Oliveira nos apresenta instigante artigo para reflexões sobre a complexidade dos museus como lugares de memória e de cultura. Nas palavras da autora: "O ponto de partida de minhas considerações é, portanto, o reconhecimento de que os museus, ao longo de sua história, vêm atuando num universo de forças políticas, protagonizado por diversos agentes que partilham com eles intenso debate em torno da ciência e da cultura". Nos agrada o exercício realizado pela pesquisadora de entrevistas com o público do Museu Paulista da Universidade de São Paulo, para trazer à tona as falas, concepções e os usos que o público visitante faz da instituição.

Com o seu olhar crítico sobre os museus salesianos, Aramis Luis Silva no oferece um "texto" cruzando a Antropologia, a Museologia e a História. Contribui com este dossiê com a questão da ressignificação de objetos e/ou coleções museológicas como condição para uma reconfiguração e reatualização desses objetos e da instituição, posto que novos paradigmas para os museus nos mostram que os sentidos atribuídos precisam ser ressignificados para a permanência, ou não, dos objetos no acervo museológico, com isso argumenta, com a circunstância apresentada, que essa elaboração não é simples e muito menos inocente.

Ana Gonçalves Magalhães centrou suas reflexões sobre o processo de formação do acervo Bienal/MAM/MAC USP, revisando a historiografia, aproxima uma visão de arte à constituição de uma coleção na década de 1950, argumen- 
ta como essa aproximação participou de um sistema internacional da linguagem artística. Traz essa discussão para a atualidade, demonstrando como outras "roupagens" se manifestam hoje, em especial na capital paulista:“...São Paulo parece ser um dos melhores lugares do mundo para ser um artista, começar uma coleção de arte e criar um museu de arte contemporânea" e também como o jogo entre a ausência de políticas públicas e mecenato limitam e/ou possibilitam novas formas de comunicação da arte.

O antropólogo Massimo Canevacci trabalha com a etnografia multilocalizada para se alcançar o projeto para o Museu Onipresente que se faz pela constelação de museus imaginários que multiplica e conecta potenciais objetos e sujeitos em espaços onipresentes e temporalidades oportunas.

Com outra abordagem antropológica, Regina Abreu etnografa os museus do Rio de Janeiro. Nos apresenta alguns resultados do projeto de pesquisa "Museus do Rio" para a qual utiliza a "etnografia audiovisual dos percursos" e a relação da memória coletiva com a dinâmica cultural. Uma das contribuições da pesquisa, segundo a autora, é o uso de ferramentas de pesquisa que permitam ainda uma relação de inter-conectividade entre ensino (de graduação e pós-graduação) com a pesquisa.

A museóloga e arte-educadora Amanda Tojal é referência em acessibilidade em museus no Brasil. Seu pioneirismo está em afirmar que as questões de acessibilidade, tão reduzidas muitas vezes, são antes de tudo uma problemática comunicacional, ou seja, não é possível pensar em acesso a museu sem pensar em comunicação museal. A partir disso conceitua acessibilidade na dimensão cultural e, com isso, democratiza a instituição museu, ao colocar cada visitante como cidadão com especificidades que precisam ser reconhecidas, respeitadas e atendidas. Apesar da legislação vigente, Tojal coloca com clareza que a postura atitudinal do museu - entenda-se, uma gestão voltada para a comunicação e a acessibilidade com equipes preparadas - deve estar amparada pelas políticas públicas sociais e para a área da cultura, em especial aquelas que impactam o museu.

Para um conjunto de autores o estudo de recepção - como me refiro - apresenta-se com diversas abordagens comunicacionais e educacionais, com métodos específicos para atender às finalidades das pesquisas que desenvolveram. A Coordenação de Educação em Ciências do Museu de Astronomia e Ciências Afins (MAST), Rio de Janeiro, está representada no dossiê por Sibele Cazelli, Carlos Alberto Quadros Coimbra, Isabel Lourenço Gomes e Esther Valente. Cabe a lembrança de que essa Coordenação é uma das poucas em museus brasileiros com um quadro de pesquisadores que se voltam ao estudos sobre educação em museus de ciência e tecnologia (C\&T), dentre eles os estudos de recepção. $\bigcirc$ artigo que essa equipe interdisciplinar nos oferece trata das percepções do visitante estimulado, para, nos parâmetros sociodemográfico, cultural e econômico, entender as relações entre empoderamento, cognição e mundo social do visitante. Chegam a constatações semelhantes às de Silvia Alderoqui e Amanda Tojal: a inclusão do visitante no museu acontece com uma política institucional. $O$ pesquisador da área de Museologia e Educação em Museus do Museu de Arqueologia e Etnologia da Universidade de São Paulo, Camilo de Mello Vasconcellos, apoiado pela concepção de aprendizagem significativa, aborda em seu artigo a importância da pesquisa sobre coleções, a comunicação pelas exposições e a educação como estratégia de apropriação. Para tanto, a experiência de visitação significativa é levada como fator preponderante, por isso a 
aprendizagem será significativa também. Nesse sentido, o autor nos expõe com clareza porque a aproximação entre os conceitos que o visitante leva ao museu e aqueles que leva como forma de apropriação é importante para entender o museu e o próprio público e, nisso, o papel do educador como agente de comunicação. Cristiane Eugênia Amarante, educadora e arqueóloga, enfrentou um público muitas vezes desconsiderado - a criança - e a construção de um multimétodo, recurso da Comunicação para construção de instrumental para apreensão da realidade empírica. $A$ autora vai além da coleta de dados, ela provoca situações para geração de dados carregados de significados, um processo em que as crianças, sujeitos da pesquisa-ação, atuam criativamente manifestando-se culturalmente na relação com a cidade de Santos, SP, para estruturar a conceituação de um museu de arqueologia subaquática na cidade, ou seja, a musealização construindo o estatuto conceitual de uma nova instituição, tendo o público como elemento constitutivo.

Bem, temos neste dossiê um conjunto significativo de artigos, autores renomados com suas reflexões e contribuições específicas que, no todo, se apresenta como um panorama bastante diversificado, destacando a Museologia crítica, mas também que a crítica aos museus passa pela comunicação, pela participação do público e pela recepção, como forma de entendimento do público visitante na sua dimensão cultural, como um representante da sua cultura que entra no museu e que o museu desconhece.

Convidamos a todos a desfrutarem do dossiê, esperando que resulte em muitas discussões.

E sem perder a oportunidade, agradeço imensamente à Revista Museologia \& Interdisciplinaridade pelo espaço para criar novas inquietações.

\section{Referências}

BOLAÑOS, María. La memoria del mundo: Cien años de museología [19002000]. Gijón:TREA, 2002.

CAMERON, Duncan F.The museum: a temple or the forum. Curator, New York: American Museum of Natural History, v. I4, n. I, p. I I-24, mar. 1970.

CAMERON, Duncan F.A viewpoint: the museum as a communications system and implications for museum education. Curator, v. I I, n. I, p. 33-40, 1968.

CURY, M. X. Museologia. Novas tendências. In: GRANATO, Marcus (Org.). Museu e Museologia. Interfaces e perspectivas. Rio de Janeiro: MCT: MAST, 2009. Disponível em: http://www.mast.br/livros/mast_colloquia_II.pdf.

CURY, M. X. Comunicação museológica: Uma perspectiva teórica e metodológica de recepção. Tese (Doutorado em Ciências da Comunicação) - Universidade de São Paulo. São Paulo, 2005.

KNEZ, E. I.;WRIGHT,A. G. The museum as a communications system: an assessment of Cameron's viewpoint. Curator, v. I3, n. 3, p. 204-2 I 2, 1970.

LOPES, Maria Immacolata Vassalo de. Estratégias metodológicas da pesquisa de recepção. Revista Brasileira de Comunicação, São Paulo: INTERCOM, v. I6, n. 2, p. 78-86, jul./dez. 1993.

MILES, Roger S. L'évaluation dans son contexte de communication. In: SCHIELE, Bernard. Faire voir, faire savoir. La muséologie scientifique au présent. Québec: Musée de la Civilisation, I989. p. I45-I55. 